\title{
Representação da identidade brasileira através do desenho animado Irmão do Jorel
}

\author{
Representación de la identidad brasileña a través del dibujo animado \\ Irmão do Jorel
Representation of the Brazilian identity through the cartoon Irmão do Jorel

\author{
Joyce Silva Cardoso ${ }^{1}$ \\ Julia Silveira Matos ${ }^{2}$
}

\begin{abstract}
Resumo
O presente trabalho tem como objetivo identificar possíveis identidades e culturas brasileiras presentes no desenho animado "Irmão do Jorel" (veiculado no canal de tv por assinatura Cartoon Network - América Latina), para que, desse modo, este desenho venha a contribuir tanto no ensino de história quanto para aproximar os estudantes da História. O desenho animado é relacionado ao cotidiano brasileiro e desse modo, visa aproximar o aluno do assunto que podem ser abordados através dos episódios, como, por exemplo, assuntos relacionados ao meio ambiente, questões de gênero, trabalho infantil, relações interpessoais. Dessa forma, utilizando-se das relações e características do cotidiano, além do "sentimento de pertencimento", para que estes sujeitos tenham a possibilidade de se enxergar enquanto agentes históricos, e não apenas ver os "grandes heróis" ou "grandes governantes". Tendo em vista que, os desenhos estão presentes nos diferentes tempos históricos e nos diferentes povos, a utilização de desenhos através da História não é algo novo, e isso pode ser observado através dos séculos. Pode observar como exemplo, os desenhos utilizados como uma forma de comunicação na "pré-história", contando, principalmente, as situações do cotidiano. Para fazer essa análise, foi utilizado autores brasileiros que abordam questões do cotidiano, sobre a cultura e identidades, além dos autores que pesquisam sobre a utilização de diferentes recursos pedagógicos no ensino. Também foi utilizada a metodologia de análise de conteúdo. Este trabalho faz parte da produção do "Trabalho de Conclusão de curso".
\end{abstract}

Palavras-Chave: cultura; desenho animado; ensino; identidade; Irmão do Jorel.

\section{Resumen}

El presente trabajo tiene como objetivo identificar posibles identidades y culturas brasileñas presentes en el dibujo animado "Irmão do Jorel" (transmitido en el canal de televisión por suscripción Cartoon Network - América Latina), para que, de este modo, este diseño contribuya tanto en la enseñanza de historia como para acercar a los estudiantes de la historia. El diseño animado se relaciona con el cotidiano brasileño y, de este modo, pretende acercar al alumno del asunto que pueden ser abordados a través de los episodios, como por ejemplo, asuntos relacionados con el medio ambiente, cuestiones de género, trabajo infantil, relaciones interpersonales. De esta forma, utilizando las relaciones y características de lo cotidiano, además del "sentimiento de pertenencia", para que estos sujetos tengan la posibilidad de verse como agentes históricos, y no sólo ver a los "grandes héroes" o "grandes gobernantes". Teniendo en cuenta que los dibujos están presentes en los diferentes tiempos históricos y en los diferentes pueblos, la utilización de dibujos a través de la historia no es algo nuevo, y esto se puede observar a través de los siglos. Puede observar como ejemplo, los diseños utilizados como una forma de comunicación en la "prehistoria", contando, principalmente, las situaciones de lo cotidiano. Para hacer este análisis, fueron utilizados autores brasileños que abordan cuestiones de lo cotidiano, sobre la cultura e identidades, además de los autores que investiga sobre la utilización de diferentes recursos pedagógicos en la enseñanza. También se utilizó la

\footnotetext{
${ }^{1}$ Discente do curso de História Bacharelado da Universidade Federal do Rio Grande - FURG; Rio Grande, Rio Grande do Sul, Brasil; joycepsilvac@gmail.com

${ }^{2}$ Prof ${ }^{a}$. Dra. dos cursos de História na Universidade Federal do Rio Grande - FURG; Rio Grande, Rio Grande do Sul, Brasil; jul_matos@hotmail.com
} 
metodología de análisis de contenido. Este trabajo forma parte de la producción del "trabajo de conclusión de curso".

Palabras claves: cultura; dibujo animado; educación; identidad; Irmão do Jorel.

\begin{abstract}
The present work aims to identify possible Brazilian identities and cultures present in the cartoon "Irmão do Jorel" (syndicated on the Cartoon Network - Latin America), so that this design will contribute both to teaching and to bring students closer to history. The animated cartoon is related to the Brazilian daily life and, in this way, aims to bring the student closer to the subject that can be approached through the episodes, as, for example, subjects related to the environment, gender issues, child labor, interpersonal relations. Thus, using the relations and characteristics of daily life, besides the "feeling of belonging," so that these subjects have the possibility of seeing themselves as historical agents, and not only see the "great heroes" or "great rulers." Since drawings are present in different historical times and in different peoples, the use of drawings through history is not something new, and this can be observed through the centuries. You can see as an example, the drawings used as a form of communication in "prehistory", counting, mainly, the daily situations. In order to do this analysis, we used Brazilian authors that deal with daily issues, culture and identities, as well as authors who investigate the use of different pedagogical resources in teaching. The methodology of content analysis was also used. This work is part of the production of the "Course Completion Work".
\end{abstract}

Keywords: culture; cartoon; teaching; identity; Irmão do Jorel.

\title{
1.Introdução
}

Neste trabalho busca-se analisar as representações da cultura brasileira no desenho animado "Irmão do Jorel", escrito por Juliano Enrico. Este desenho animado foi estreado no ano de 2014 no canal de televisão por assinatura, Cartoon Network. Mas, está disponível na plataforma de streaming do YouTuBe.

A utilização de desenhos através da História não é algo novo, e isso, pode ser observado através dos séculos, principalmente para comunicar situações do cotidiano. Colocando a chamada "pré-história" como exemplo, é possivel encontrar os desenhos produzidos pelos homo sapiens como uma forma de comunicação. Esses desenhos são conhecidos como "pinturas rupestres" e, normalmente, encontravam-se nas paredes das cavernas. Além disso, era uma forma de comunicação, emitindo suas em suas mensagens desde aviso sobre animais perigosos, até suas caçadas e situações do cotidiano.

Os desenhos estiveram presentes ao longo da história, nas diversas civilizações, apresentando suas várias ressignificações, mas, é possivel enxergar uma função em comum exercida pelos desenhos nas diversas sociedades, que é a representação do cotidiano, de como tal sociedade se via, o que era considerado importante para ela.

A utilização do cotidiano no ensino de História é um recurso pedagógico que visa a aproximar o aluno do período do qual se trata, e assim, facilitar o entendimento por parte do aluno.

A representação do cotidiano é muito forte quando se trata de desenhos no ensino de 
História. Com o aprimoramento tecnológico, os desenhos puderam tornar-se um recurso animado, e, posteriormente, apresentando sons e diálogos falados.

É necessário ressaltar que, o Brasil, por ser um território extenso, não atinge um padrão de homogeneidade cultural, entretanto, há elementos, situações, modo de pensar, enraizados nos brasileiros, podendo ser notados ao longo do país. Portanto, apoia-se em autores clássico que discutem cultura e identidade brasileira, como a autora como a Marilena Chauí (2000), Sérgio Buarque de Holanda (1995) e Capistrano de Abreu (1998), que se propõe a discutir sobre cultura brasileira. A definição de Cultura Brasileira tanto quanto de identidade nacional, apresenta variação de acordo com o autor, no período no qual ele se encaixa e define a Cultura Brasileira, desse modo, é possível ver entre os autores, ideias que são contarias ou semelhantes.

A autora Marilena Chauí, apresenta a ideia de "Cultura Brasileira" como uma invenção relacionada as tantas diferenças sociais. A cultura é uma forma de atribuir características "idênticas" ou "semelhantes" a pessoas diferentes, demonstrado uma representação homogênea que os brasileiros possuem do país e de si mesmos. Desse modo, permite-se, em certos momentos, crer em uma unidade, identidade e na indivisibilidade da nação e do povo brasileiro. Entretanto, também ocorre em outros momentos, a divisão social e a divisão política sob forma dos amigos da nação e inimigo comum a todos que precisa ser combatido, fortificando a unidade, a identidade e a indivisibilidade nacional. Essa "homogeneidade" acaba se relacionando com o "mito das três raças" discutido através das ideias do autor Gilberto Freyre. O "mito fundador", o "mito das três raças", tentam suprimir a ideia de que há descriminação e preconceitos no Brasil pois, com a "democracia racial", onde as três raças se misturam, o indígena, o negro e o branco, formam uma raça única, a brasileira, assim, muitas vezes é negada a existência de preconceito racial no Brasil.

É possivel, portanto, a partir dessa concepção da autora, perceber através da configuração familiar representada no desenho animado uma relação com o "mito fundador" e o "mito das três raças", a partir do momento em que todos os familiares, moradores da mesma casa, quase não possuem características semelhantes entre si, mas várias características que levam a enxergar as variadas composições genéticas herdadas do que faria parte do processo de miscigenação, uma característica marcante da sociedade brasileira. Essas características podem ser observadas no núcleo familiar composto por sete moradores em uma casa, outra característica bem comum, se levado em conta que a maior parte da população brasileira é composta por pobres, tendo em torno de $60 \%$ da população sobrevivendo com apenas um salário mínimo, segundo o censo do ano de 2010 do IBGE. Na imagem a seguir, por ordem de visualização, da esquerda para a direita, encontramos a mãe (Danuza), o pai (Edson), avó 
materna (Vovó Gigi), avó paterna (Vovó Juju), a mãe (Danuza), o pai (Edson), o irmão mais velho (Nico ou Nicolau), o irmão do meio (Jorel) e Irmão do Jorel que é o irmão caçula. A personagem Danuza tem um irmão (Valtinho) que apareceu em dois episódios.

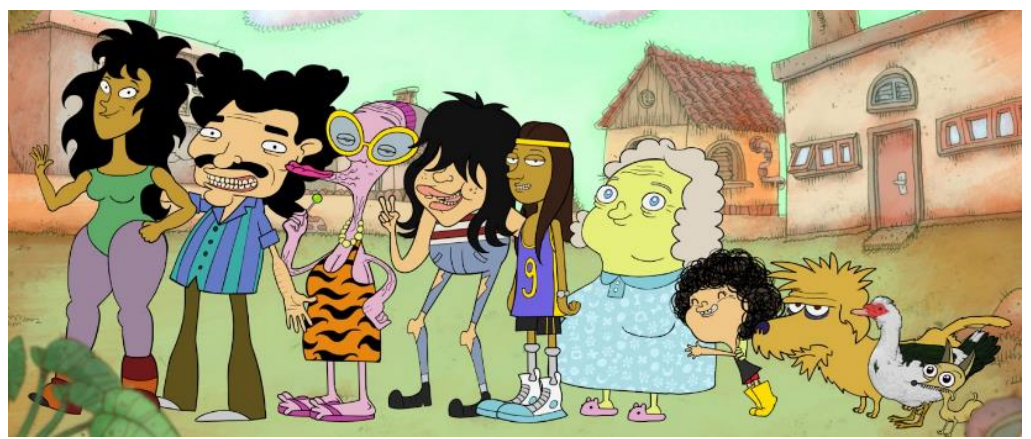

Fonte: cosmonerd.com.br, publicada dia 13 de fevereiro de 2017.

Uma questão relevante na representação dessa família é a figura da mulher, Danuza, ser colocada em primeiro lugar, antes do pai e este em segundo. Ao longo dos episódios, percebemos que a mãe desempenha um papel misto do que seria a ideia da mulher que permeia na sociedade, pois, ela é tanto a fonte de renda da familia e também faz a dupla jornada tão discutida no universo feminino. Ainda assim, pode ser observados outros estereótipos em cima da personagem, como é o fato das mulheres serem vistas como se conseguissem e tivessem a obrigação, socialmente imputada, de conseguirem "dar conta do mundo inteiro", passar a roupa, lavar a louça, arrumar a casa, cuidar dos filhos e ainda sim estar no meio de uma ligação. Como em todo o núcleo familiar, nessa personagem, fica evidente o que seria o processo de miscigenação, se observada com atenção, as características físicas, como o cabelo, silhueta e cor da pele denunciam esse processo na personagem, levando a crer que há, neste personagem, a "mistura das três raças", pois, não há características que tendem a apenas uma ou duas composições genéticas.

A figura do pai é compatível com características esperadas para o papel masculino, pois, raramente o vemos fazendo alguma tarefa doméstica, porém, ao mesmo tempo, raramente o vemos punindo as crianças por estarem fazendo alguma coisa fora do esperado. Este personagem, muitas vezes, é apresentado como um homem adulto que não enxerga ou não quer enxergar as suas responsabilidades. Em outra análise, podemos encontrar autoras como Luciana Lopes Lemos, em sua dissertação sobre "Representações sociais sobre planejamento familiar", na qual ela aborda, também, a questão do homem, do pai que não divide as tarefas domésticas. Além disso, este casal não é padrão em questões estéticas, em primeiro lugar, pela cor da pele da mãe ser mais escura, uma vez que, os casais socialmente representados são brancos, altos, 
magros e, no mínimo, classe média. Ainda nesse sentido, a personagem Danuza é mais alta, é representada como sendo mais forte fisicamente em relação ao marido, podendo ser observado pela estrutura dos braços e pernas dos pais. Ao tratar das características físicas do pai, percebemos que ele é um homem branco, entretanto, o próprio mito das três raças acaba fundamentando o fato de não existirem brancos puros no Brasil, fazendo com que este personagem, assim como nos demais, seja permitida a interpretação de misturas étnicas, como a estrutura do cabelo não ser lisa, ter a boca grande e o tom de pele amarelado. Mas, essa família, ainda, representa uma família heteronormativa aceita pela sociedade.

Assim como a Marilena Chauí, Sérgio Buarque de Holanda e Capistrano de Abreu também pautam a formação tanto da identidade quanto da cultura brasileira em questões étnicoraciais. Com o autor Sérgio Buarque de Holanda, a cultura brasileira pode ser vista como "neoportuguesa" e, o brasileiro, "neoportuguês", pois ele aponta que os portugueses se constituíram de forma diferente do restante dos europeus, tendo características únicas. Assim, as características atribuídas aos brasileiros, como o apreço pelo ócio é de origem portuguesa, enxerga que o indivíduo não quer alterar o mundo social, que nem mesmo reconhece e identifica. Portanto, é possível enxergar que a cultura brasileira é uma mistura da origem portuguesa com novas alterações decorrentes de outro local (Brasil) que não o originário. Ele também aponta que não há uma cultura propriamente brasileira e sim, uma cultura trazida de Portugal para o Brasil, tendo essa cultura alterada por diversos fatores, sendo assim, considera que no Brasil há uma cultura neoportuguesa. Também explica que para haver uma cultura propriamente brasileira, é preciso romper com o seu passado português. É possível ver com Sérgio Buarque, a importância, a centralização do português para a formação da cultura brasileira e que a nossa cultura — instituições, ideias, formas de convívio — veio de outro lugar e não se adaptou aos trópicos.", portanto, a cultura brasileira é, neste viés, considerada uma cultura neoportuguesa.

Com o autor Capistrano de Abreu, é possível encontrar uma crítica em relação a Freyre e a tese de democracia racial, pois, entendia que o mestiço tinha uma vida difícil também e era visto com aversão na sociedade, além de ser impossibilitado de ocupar os mesmos cargos que os brancos ocupavam. É possível ver também, que as histórias de lutas pela independência, o povo brasileiro e principalmente, o indígena, são importantes para a formação da cultura brasileira. $\mathrm{O}$ autor afirma, também, que o brasileiro é um europeu que sofreu um processo de diferenciação por causa do clima e da miscigenação com o indígena. Contudo, Capistrano expressa sua visão como "anti-portuguesa", "anti-europeia", colocando como parte fundamental o indígena e afirmando que o Brasil era mais mameluco e mais sertanejo. $\mathrm{O}$ autor 
se refere, principalmente, ao período de um Brasil colonial e em sua obra, utiliza do termo cultura para substituir o termo raça, portanto, uma das possibilidades de definição da cultura brasileira, está fundamentada na miscigenação, principalmente na apontada por ele, entre índios e europeus. Nesse sentido, ele apresenta o europeu e o negro como elementos exóticos. O europeu é visto como imigrante, invasor conquistador e colonizador e o negro com índole carinhosa, mas também como o outro de outra terra, como o autor afirma (1998, p. 29) "Ao português estranho ao continente cumpre juntar o negro, igualmente alienígena.”. Com suas escolhas de palavras, portanto, pode-se levar a entender a valorização do que é originário do Brasil, o clima, o indígena, sendo assim, a cultura brasileira na visão de Capistrano de Abreu, pode ser vista, principalmente, como vinda do indígena, relacionada ao indígena e de origem das terras do Brasil, desse modo, sua visão não é aristocratizante, senhorial, elitista em comparação aos seus contemporâneos.

Desse modo, pode-se observar que os autores que pensam a sociedade brasileira, tendem a relacionar a formação cultural e indenitária com questões étnicas-raciais. Para elucidar com mais clareza as situações cotidianas que possam ser discutidas em sala de aula, junto com algum assunto escolhido, é utilizado dois episódios como exemplo.

O primeiro episódio é o "Fúria e Poder Sobre Rodas" o principal tema abordado é a questão de gênero, que é levantada durante um diálogo entre as crianças, Lara e o Irmão do Jorel. Nele, surge um questionamento do menino sobre a conotação do sentido da palavra "mulherzinha", que em geral, é utilizado como um adjetivo pejorativo, ou seja, é sempre utilizado para imputar fragilidade, fraqueza e vulnerabilidade. Neste episódio a personagem Lara, chama o Irmão do Jorel de "frangote" (substantivo masculino, significa pequeno, frágil, fraco) e ele questiona se estava sendo chamado de "mulherzinha", portanto, frangote e mulherzinha são colocados como sinônimos. O emprego dessa palavra demonstra o machismo intrínseco na sociedade, pois, é utilizado para diminuir mulheres, além de ser afirmar que ser "mulherzinha" ou seja, ser mulher é um defeito, demonstra que não há um questionamento, tampouco um debate sobre o porquê da palavra ser empregada dessa forma e ter esse sentido. Pode ser observado que é utilizado para praticar bullying e debochar de homens, diminuindo-os perante as demais pessoas, pois acabam sendo comparados com mulheres (que são socialmente colocadas como inferiores). Além disso, é levantada a questão sobre haver brinquedo destinados a meninas e a meninos, assim somo esportes separados, como é exemplo do "Roller derby". 
Outro episódio é o "Embarque Nessa Onda", no qual é possível enxergar uma crítica em relação a forma de consumo da sociedade e de como esse consumo se relaciona com o meio social.

Nesse episódio, Irmão do Jorel acaba ficando deslocado entre as crianças por não ter assistido a estreia de um novo desenho animado, chamado "Microwave Warriors", onde os personagens são fundidos com eletrodomésticos e lutam contra vegetais. No dia seguinte ao da estreia, as crianças, adolescentes e adultos compram brinquedos, brincam e falam somente de "Microwave Warriors". Posteriormente, os brinquedos começam ter defeitos, fazendo com que as crianças se machuquem. Assim, no mesmo dia em que o desenho foi cancelado, já estreou outro desenho no lugar.

Sendo assim, torna-se viável levantar discussões sobre o sistema capitalista, produção e consumo rápido, relações com esse tipo de produção e o meio ambiente, entre outras questões que podem ser levantadas. De modo geral, muitos episódios trazem referências da cultura brasileira, seja com os personagens, com as situações, diálogos ou vestimentas, ao mesmo tempo em que há episódios no qual não aparecem, de fato, assuntos ligados a cultura brasileira, tampouco com a área de História, pois, este desenho não foi criado especificamente pensando na área de História, mas sim, apresenta um cunho autobiográfico do autor, o qual é brasileiro, portanto, há muitas características culturais. É necessário ressaltar a existência de um olhar lúdico referente ao de uma criança, pois, o desenho foi criado para o público infantil. Sendo assim, em muitos momentos o desenho apresenta situações totalmente irreais.

\section{Considerações Finais}

Com novas pesquisas sobre o ensino e aprendizagem, as transformações na área de História, as reflexões acerca da formação dos docentes, os debates sobre o ensino de História, a compreensão sobre a necessidade de entender que a formação histórica do aluno não acontece apenas dentro da sala de aula, mas fora, no seu cotidiano possibilitou com que a aprendizagem do conhecimento histórico não ficasse voltada apenas na figura do professor dentro da sala de aula.

Esses debates e as novas percepções sobre fontes para o ensino estão aos poucos superando os meios e visões tradicionais da História, e novos conteúdos abordados, transformam a formação do docente, que, por sua vez, auxiliam em uma nova compreensão do aluno, do aluno sobre o professor e do professor sobre o aluno. Segundo o autor Marcos Napolitano (2010, p. 149), "Nos últimos anos tem sido cada vez mais frequente o uso de "novas linguagens" não só para motivar os alunos, mas para tentar "atualizar" a concepção 
de documento histórico, incluindo-se neste campo as imagens (paradas e/ou em movimento).”. Ou seja a contribuição do ensino de história não se restringe apenas a matéria escolar.

Torna-se visível a facilidade de combinar o desenho animado com o ensino, uma vez que, a televisão se faz tão presente no cotidiano brasileiro, e o desenho animado, por sua vez, acaba participando desse cotidiano.

O autor Waldomiro Vergueiro, no livro "Como usar As histórias em quadrinhos na sala de aula", conta sobre o processo de utilizar as histórias em quadrinhos enquanto um recurso didático - pedagógico novo, para isso, foi necessário contextualizar o surgimento das HQS, que inicialmente eram sátiras de jornais no final do século XIX nos Estados Unidos. Na tentativa de elucidar melhor a sua defesa, o autor explica que as mudanças na forma de ensino surgem de acordo com a necessidade do ambiente atual. Para tanto, é abordada a introdução da imagem como forma de comunicação, sendo essa, um método antigo utilizado desde os tempos da caverna.

Portanto, é possível utilizar o desenho animado "Irmão do Jorel” enquanto um recurso didático para auxiliar em conteúdos trabalhados pelos professores. Dentre esses conteúdos, destaca-se História do Brasil, pois, nesse conteúdos, ao falar da chegada dos portugueses e da formação da sociedade brasileira depois, encontra-se o processo de miscigenação, que torna-se explicito na composição étnica da família do irmão do Jorel. Assim como é possivel abordar diferentes questões, como cidadania, gênero, meio ambiente, consumo, entre outras possibilidades.

\section{Referências}

ABREU, Capistrano de. Capítulos da história colonial. $1^{\mathrm{a}}$ edição. Brasília: Conselho Editorial do Senado Federal, 1998.

AMORIM, Roseane Maria. SILVA, Cintia Gomes. $O$ uso das imagens no ensino da História: reflexão sobre o uso e a interpretação das imagens dos povos indígenas. Londrina. História \& Ensino, v. 22, n. 2, p. 165-187, jul./dez. 2016. Disponível em: <http://www.uel.br/revistas/uel/index.php/histensino/article/viewFile/26263/20301>. Acesso em 10 agosto de 2018.

BARDIN, Laurence. Analise de conteúdo. Lisboa, Portugal: Editora Edições 70, 2009. Tradução 2011, Editora Almedina.

BITTENCOURT, Circe. (org.). O saber histórico na sala de aula. 11 edição. São Paulo: Editora Contexto, 2009. 
BURKE, Peter. $O$ que é história cultural?. 2 edição. Rio de Janeiro: Editora Zahar, 2008. 215 páginas.

CERTEAU, Michel de. A Invenção do cotidiano. 18 edição. Tradução de Epheraim Ferreira Alves. Petrópolis, Rio de Janeiro. Editora Vozes, 2012.

CHAUÍ, Marilena. Brasil - Mito fundador e sociedade autoritária. $1^{\text {a }}$ edição. São Paulo: Editora Fundação Perseu Abramo, 2000.

FIORIN, José Luiz. A construção da identidade nacional brasileira. BAKHTINIANA, São Paulo, v. 1, n. 1, p. 115-126, 1o sem. 2009. Disponível em: <http://revistas.pucsp.br/index.php/bakhtiniana/article/view/3002/1933 >. Acesso em: 22 setembro de 2018.

FREYRE, Gilberto (2006) Casa Grande e Senzala. 51ª ed. São - Paulo. Global Editora.

FUSARI, Maria Felisminda De Rezende e. O educador e o senho animado que a criança vê na televisão. São Paulo: Editora Edições Loyola, 1985.

GOMES, Lizandra Ogg. O cotidiano, as crianças, suas infâncias e a mídia: Imagens concatenadas. Campinas (SP). Pro-Posições, v. 19, n. 3 (57) - set./dez. 2008. Disponível em: <http://www.scielo.br/pdf/pp/v19n3/v19n3a09.pdf $>$. Acesso em: 10 agosto de 2018.

HOLANDA, Sérgio Buarque de. Raízes do Brasil. 26a edição. São Paulo: Companhia das Letras, 1995.

INTERESSANTE, Revista Super. Reportagem online de 04 de novembro de 2016. Disponível em: $\quad<$ https://super.abril.com.br/cultura/batemos-um-papo-com-juliano-enrico-criadordoirmao-do-jorel/>. Acesso em: 15 agosto de 2018

LEMOS, Luciana Lopes. Representações sociais sobre planejamento familiar. Rio de Janeiro - RJ. Dissertação de mestrado, 2013. Disponível em: <http://www6.ensp.fiocruz.br/repositorio/sites/default/files/arquivos/RepresentaçõesSociais.p df $>$. Acesso em 2 outubro de 2018.

LIMA, Joélica Pereira. O desenho animado como recurso didático: uma intervenção no ensino médio. Campina Grande (PB). Monografia 2014. Disponível em: <http://dspace.bc.uepb.edu.br/jspui/bitstream/123456789/5624/1/PDF\%20\%20Joélica\%20Per eira\%20de\%20Lima.pdf>. Acesso em 12 agosto de 2018.

MONTEIRO, Ana Maria. GASPARELlO, Arlette Medeiros. MAGALHÃES, Marcelo de Souza. (org.). Ensio de História - Sujeitos, saberes e práticas. 2 edição. Rio de Janeiro: Editora Mauad X, 2009.

NAPOLITANO, Marco. A televisão como documento (in: O saber histórico na sala de aula. 11 edição). São Paulo: Editora Contexto, 2009 
RAMA, Angela. VERGUEIRO, Waldomiro. BARBOSA, Alexandre. RAMOS, Paulo. VILELA, Túlio. (org.). Como usar as histórias em quadrinho na sala de aula. $4^{\text {a }}$ edição. São Paulo: Editora Contexto, 2012.

RIBEIRO, Darcy. O Povo Brasileiro: evolução e o sentido do Brasil. São Paulo,1995. Editora Companhia das Letras.

SCHMIDT, Maria Auxiliadora. A formação do professor de História e o cotidiano da sala de aula (in: $O$ saber histórico na sala de aula. 11 edição). São Paulo: Editora Contexto, 2009 